\title{
It's not just English, it's complicated: Approaching at-risk college students' academic language remediation
}

Cacho, Reynald M.

Philippine Normal University, South Luzon Campus, Philippines (cacho.rm@pnu.edu.ph)

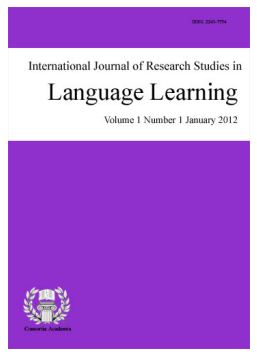

\section{Abstract}

This article reports an alternative assessment of at-risk college students' second language and academic literacy skills, and their awareness and experiences in learning English as Second Language (ESL) for deeper understanding of such students' challenges and opportunities. Fifty-one freshmen grantees of the Expanded Students' Grant-in-Aid Program for Poverty Alleviation (ESGP-PA) in a state university from the Philippines participated in this study mounted on a quantitative-qualitative research design. Results of summative academic literacy tests revealed that the students found considerable level of difficulty in negotiating with meaning and form of college-level language tasks. Problematique analysis of their journals suggests influential factors that could impact at-risk students' success and failures in college language and literacy instruction. Implications for approaching student-centered-classroom-based English language remediation program are advanced.

Keywords: at-risk college students; academic literacy; study skills; grammar; problematique analysis; remediation 


\section{It's not just English, it's complicated: Approaching at-risk college students' academic language remediation}

\section{Introduction}

Difficulties in learning English for at-risk college students are not new. Helping at-risk students succeed in their post-basic education journey is an evolving university program toward increasing equity and access. Access to higher education in the Philippines is apparently within reach by such college students availing various sorts of scholarships. Remediating their language competence and academic deficiencies to make them comfortable to navigate the college level lane, however, is a different story. Academic literacy instruction, as cited in related studies (e.g. Brown, 2002; Curry, 2003; Curry, 2004; Doloughan, 2001; Lee, 2011; Wallace, 2007) which connects and aids learners to other university courses — not only focused on the linguistic competence, reading comprehension, and study skills but also on the development of highly driven learners, is gaining ground; as a result, university designs programs for at-risk college students for them to meet the communicative and scholastic demands of tertiary education. As a language and literacy instructor, I am frequently involved in planning and implementing specific classroom activities that should fit to my at-risk college students. Whether these activities are effective or not for have yet to be seen.

The need to employ effective literacy programs is high; at-risk college students should become successful readers. If they cannot perform well in a simple reading activity, this may deter their learning in other areas. Benesch (1998) perceived that many freshmen enter college only to struggle in certain linguistic and academic activities such as reading critically, taking notes from readings and lectures, formulating questions and writing logical essays. On the other hand, students who have different learning orientation may face many academic challenges and failures, which more likely influence their attitude toward learning (Curry, 2004; Donnelly, 1987; Lei et al., 2010; Lee, 2011). Apparently, they lack the necessary skills that warrant academic success. They need sufficient vocabulary in order to read independently. Not surprisingly, literacy gap on vocabulary acquisition expands between at-risk and advantaged students throughout the schools (Vitale \& Romance, 2012). Furthermore, English Language Learner (ELL) not only take English courses as prescribed in program but also attend content courses, like Math and Science, which are all delivered in English - their second language. Curry (2004) added that they should not only have the basic skills but they must also learn the technical practices of academic reading, writing, and speaking that demonstrate college-level communication.

To guarantee access to and success in college education, the Philippine government introduced and implemented the Expanded Students' Grant-in-Aid Program for Poverty Alleviation (ESGP-PA). According to the Commission on Higher Education (2012), this program aims to contribute to the national government's thrusts in effectively addressing poverty alleviation by increasing number of graduates in higher education among poor households. When financial matters are taken care of, the main concern for ESGP-PA student grantees, apart from their physical and emotion well-being; is their mental capacity to hurdle the rigorous academic college works. Hence, it is just timely for Lei, Berger, Allen, Plummer, and Rosenberg (2010) to observe that college students learning English as their second language are faced with dilemmas concerning reading, writing, speaking, and listening at the college level.

Instructors of the ESGP-PA students in a Philippine university, lament that, if not all, majority of such students are considered at-risk of failing. Their low test scores and poor performance speak more of this unfavorable condition. They have struggled to survive for two trimesters not to mention that four out of the fifty-eight grantees have already dropped. Other than enrolling them in the prescribed courses, a state university with ESGP-PA students can support such learners by implementing strategies and programs. Thus, this state university offered a remedial program dubbed as 'Tulay Pa-Normal' (Bridge to College Education). This bridging program spanned for two weeks covering one essential subject per day, of which I was assigned to 
It's not just English, it's complicated: Approaching at-risk college students' academic language remediation

handle a remediation session in English. After two trimesters of studies in a university, we found it interesting and beneficial to determine the students' current knowledge and skills level; this study is also important in order to determine the least learned skills and concepts in a recent course they have taken and their awareness and experiences in learning the second language of which I can draw empirical data as bases of understanding deeply the learners and enhancing the current university language remediation program. For these reasons, the following questions were addressed:

$>\quad$ How do at-risk college students perform in language test that covers reading comprehension and study skills, and grammar? What are their least learned skills?

$>\quad$ What do their journals say on their attitude and experiences in learning English?

\section{Literature Review}

Donnelly (1987) describes common at-risk students as students who are not succeeding in school and are more likely to dropout. Generally, they are low academic performers who have little or no confidence at all in their learning which is even aggravated by their low socioeconomic status. It is advanced further that "students who are both low income and minority status are at higher risk; their parents may have low educational backgrounds and may not have high educational expectations for their children" (Donnelly, 1987, p. 2). With deep reflection, Hernandez (2011) assumes that such students who are failing classes and disengaged cannot be viewed categorically as potential college students.

With the resurgence of study grants in the Philippine landscape particularly the Expanded Students' Grant-in-Aid of Poverty Alleviation (ESGP-PA), more and more students from poor households turn to state universities for access to higher education. Since widening college participation is at the helm, academically-challenged ESGP-PA students enter with fewer restrictions the university programs that address their deficiencies making a college diploma within their reach. In order to achieve this goal, Benesch as cited in Curry (2004) argues that academic literacy remains to serve a vital role in the experiences and retention in a college program. In its absence, students may not survive the rigorous examinations and other course requirements that entail huge lists of reading and writing; thus they are more inclined to failing or to make matter worse dropping out.

Granted that more students are participating in higher education, majority of students recruited for ESGP-PA may not successfully negotiate "the communicative demands of the academy—chiefly through academic writing and can persist in education" (Curry 2003, p. 6). Instructors are worried invariably about college entrants' academic writing skills of grammar, spelling, and punctuation. In a case study report, Curry, however concludes that one of the factors why some ELLs dropped out in writing course, is that instructors lack extensive training and experiences in teaching English as foreign/second language. This is manifested by their reliance on the use of skills model of teaching academic writing which is deemed insufficient to meet the goal of writing; hence skills model focuses on student error rather than building their existing competencies which in turn compromises students' self-esteem, creativity and individuality (Curry, 2004; Doloughan, 2001).

Supporting the need for enhanced instruction, Lei et al. (2010) admitted that ELL college students are faced with dilemmas concerning reading, writing, speaking, and listening at the college level. In line with this, these students are strained in achieving the level necessary to function at the degree expected of them. This issue not only concerns the students but also their college instructors to strive for it that may not be achieved rapidly or briefly. Moreover, Brown (2002) expresses that language learning is not simple as a programmable 'quick do-it-yourself kit.' Not even courses in foreign languages suffice the complete requirements for the successful learning of a second language. Complicating this matter, Lee (2011) stresses the fact the primary language spoken by struggling ELLs at home is not English. Thus, it is necessary to beef up instruction to at-risk students by providing structure in the classroom, showing connection between classroom learning and the real world, and making students accountable for their own learning. 
Learning second language inside and outside the university campus necessitates not only stable financial resources and the right attitude, but also practice and sheer grit by all students, instructors and stakeholders involved in the learning environment. On one hand, even if some learners have fluent oral vocabulary, majority still find difficulty that they must exert more than the usual effort to achieve the reading level necessary and fitting to their grade level (Wallace, 2007). By and large, vocabulary development is the lifeblood toward becoming good readers in any academic subject areas. Having said so, Lei et al. (2010) have the privilege to state that "If in order to successfully complete, any college-level courses, ELL must be able to read and comprehend a large volume of academic information (Lei et al., 2010, p. 92)" to include also having positive attitude toward reading, increasing vocabulary, using dictionaries, note-taking, and signal devices, as well as repeated and extensive reading.

Assia and Said (2014) claim that "learning a foreign language cannot be realized without grammar which is thought to furnish the basis for a set of language skills: listening, speaking, reading and writing" (p. 86). Generally, grammar holds its grounds on language learning and teaching processes where language development cannot take place effectively if learners do not have considerable knowledge of it. Linguists define "grammar as the set of structural rules that governs the composition of clauses, phrases, and words in any given natural language" (Praise \& Meenakshi, 2015, p. 98). Without these standards language will seize to continue and, encoding and decoding of ideas will likely be affected to a certain degree. Much more, at-risk college students, who lack proper grammatical or linguistic knowledge, will be unable to correct by themselves the grammatically errors they vulnerably commit consciously or not; consequently, this becomes the focus of the current study to investigate whether such assumption is true among freshmen students considered at risk.

By means of a qualitative and quantitative approach, Assia and Said (2014) investigated the impact of small group interaction on English as Foreign Language (EFL) learners' grammatical achievement. Their study results suggest that learners' interaction and cooperation had a positive effect on EFL learners' achievement. Adopting the Interaction analysis model, it was revealed that within a cooperative learning context, factors such as the group size; the nature of the interaction; the learner's role within the small group, and the type of the task-based grammatical structure had an influential effect on EFL learners' grammar performance. Notably, learning anxiety became apparent in group activities. The fear of being laughed at and dependence among other peers were apparent in big groups compared to small ones. Focusing on students' attitude and preferences towards learning English in Kuwait universities, Al-Bustan and Al-Bustan (2009) confirms that the inclination to learn a language and succeed rests more on how students connect their learning experiences which include either the past and present success or failure, favorable or otherwise.

Although there is a relatively rich body of literature exploring the issues of college students' academic language and academic performance in learning English, much of it focused primarily on students' linguistic knowledge. Much more, the literature indicates that there is little research on intact at-risk college students' particularly for state-scholarship grantees in the Philippines. Understanding its primary concerns, the current study covers to assess the academic literacy skills, grammatical knowledge - although this did not intend to deeply explore the nature of linguistic errors - but rather offer an alternative examination and picture of such language knowledge and awareness of at-risk freshmen students towards strategic planning and implementing of an enhanced language bridging program and deep understanding of the learners' experiences for them to reach the finish line away from and/or prepared for the risky roads brimming along the college lane.

\section{Methodology}

\subsection{Design}

After pondering deeply on the aforementioned research objectives, the researcher found it more appropriate to adopt evaluative design combining quantitative and qualitative approaches. To collect information about the 
It's not just English, it's complicated: Approaching at-risk college students' academic language remediation

reading comprehension, study skills and grammatical competence of the at-risk students, a criterion-reference diagnostic test was employed. Moreover, this kind of tests evaluates specific materials and skills (Brown, 2002; Griffe, 2012). Here, it is composed of two parts, of which the specific skills and content coverage, and the number of items per area are found on Table 1 and 2 in the result section. Basically, part 1 consists of 35 items with multiple choices. It covers the basic academic literacy skills for college students while the second part is composed of 65 items dealing with grammatical competence.

In order to triangulate the results of the language and literacy test and to answer the second research question, a clinical elicitation strategy followed "by asking research participants to produce some data which was then analyzed" (Vasquez 2008, p. 136). In doing so, the researcher requested the students to write journal composition about the topic “My Worst and Best Experiences in Leaning English”. Griffee (2012) claims that students may suppress their ideas and feelings about classroom learning if it is done in whole class; thus journal writing may give them the opportunity to share some learning concerns with more confidence between the instructor and students. Such writing also enriches the students' desire to learn because it needs self-examination that also allows teachers to deepen understanding (Genesse \& Upshur, 1996) and be more sensitive to the needs of the learners. Since this writing requires time, all students who took part in the initial test handed over their compositions the next day.

\subsection{ESGP-PA At-risk Students and Bridging Program}

The at-risk students, mentioned at the introductory part of this report, come from a Philippine university. Purposively chosen, they are the intact group of respondents to this study. At the beginning of the first trimester, they were fifty-eight students who were able to avail the national government's ESGP-PA - primarily because they hailed from poor households who rely on state financial aid to secure college education. Through the ESGP-PA, at-risk student grantees receive monthly stipend, payment for matriculation fees, book and dormitory food allowance while they are taking a university program (Commission on Higher Education, 2012). Almost all of them were considered the first family member who first entered college. For apparent academic failures and weak coping mechanisms, four of them had dropped. To address poor performance and glooming attrition, the remaining fifty-four students were required to take the university's remedial program, and which it would prepare them for the succeeding trimesters. At the first remedial session in English subject under the 9-day bridging program—dubbed as 'Tulay Pa-Normal' (Bridge to College Education) wherein each day is allotted to specific subject area, data gathering was initiated.

\subsection{Ground Works and Data Analyses}

The English language and literacy test material were sampled and validated to cover the key contents and references of the course English for Academic Purposes which the at-risk students had just completed before the bridging program. Some items from various online and offline resources were adopted, modified and/or tailored fit to connect with the learners cultural and background experiences and orientation. To increase reliability, the same test was piloted as final examination to three regular classes of freshmen not considered at risk. Results of the piloting show consistency within the three groups of students. Understanding the least learned skills from the tests dictated getting the frequency count and percentage of correct responses and sentence-level errors. Generally, language researchers regard frequency count as an objective way of describing a composition. More than the forms are the meanings or messages of the journals. Students narratives comprised languages which Jou (2013) framed as "socially constructed and practiced, language use, in a sense is socio-culturally situated cognition, emerging in the dynamics of social constructions and negotiation" (p. 50). Here sociolinguistic semantic terms in the journals were examined. Finally, to make sense insightfully of the 'Best and Worst Experiences in English' learning entries, a problematique analysis (Librero, 1993) was then employed; recurring problems or issues raised in the composition were analyzed focusing on the causes or symptoms of problems and the presented in a problematique map. 


\section{Results and Discussions}

\subsection{The Need to Address Academic Literacy}

Table 1 presents the overwhelming results that could explain why fifty-one college students were considered at risk of failing academic courses that demand extensive reading and college-level writing outputs. The frequency of scores suggests that comprehending an English academic text through writing an outline and/or a summary would be the most difficult task for these students; consequently, this confirms the dilemmas faced by the college students concerning reading academic texts and college-level writing (Lei et al., 2010). Worth noticing also was the fact that, in the absence of dictionaries, at-risk college students must learn to optimize decoding context clues, connotation, and affixes in order to grasp the meaning of a sentence or paragraph; doing so would become another challenge for them to grapple. Similarly, it does not mean that when they are aware to some degree on the use of academic references like dictionaries, glossary, and the likes, they should become too dependent with these materials, since there are times that such materials may not be available readily and/or allowed to be used particularly during test taking.

Table 1

Frequency of Correct Responses in the Reading Comprehension and Study Skills Test (N=51)

\begin{tabular}{lccc}
\hline \multicolumn{1}{c}{ Competencies } & Number of Items & $\begin{array}{c}\text { Frequency of Correct } \\
\text { Responses }\end{array}$ & Percentage \\
\hline 1. Outlining & 3 & 39 & 25.49 \\
2. Identifying the topic sentence & 3 & 39 & 25.49 \\
3. Summarizing & 3 & 42 & 27.45 \\
4. Decoding context clues & 4 & 56 & 27.45 \\
5. Unlocking connotation & 3 & 42 & 27.45 \\
6. Analyzing expository text & 5 & 92 & 36.08 \\
7. Looking up denotation & 3 & 63 & 41.18 \\
8. Understanding affixes & 5 & 110 & 43.14 \\
9. Using academic references & 6 & 149 & 48.69 \\
\hline
\end{tabular}

\subsection{The Grammar Dilemma}

Aside from reading and study skills tests, in order for college students to progress in their program, they must hurdle the language proficiency tests focusing on grammar and related linguistic competence. Arranged from lowest down the highest percentage in Table 2, at-risk students found ostensibly a great deal in negotiating with simple, progressive, past, future and perfect aspects of the verbs, including changing direct speech to reported (vice versa), working with phrases, and the notorious prepositions; subsequently the totality of responses supports Al-Bayati's (2013) previous findings that college students did find difficulty in the use of English prepositions and phrases of which their first language could have played a vital role in any misconception. At-risk college students, in addition, struggled considerably in classifying the structure of sentence, dealing with the subject-verb agreement, and using correct cohesive markers. If at-risk college students' linguistic knowledge level continues to fall short of what is expected from them, they will more likely persist to remain at risk of failing course requirements demanding a higher-education-level communication in English.

\subsection{Challenges and Opportunities}

Figure 1 demonstrates the experiences and attitude of at-risk college students in learning English. By framing a problematique map of the themes and insights of the students' composition, incidents and influential factors of the problems in learning the target language were recognized; included were the challenges they had 
It's not just English, it's complicated: Approaching at-risk college students' academic language remediation

encountered and what they felt about them. Relying with individual narratives about language learning from sociocultural perspectives (Jou, 2013), I was able to trace these seemingly unnoticeable themes in the students' journal. Fifty-one short compositions were analyzed - ideas were coded and classified based on their relationships. Notably, two dominant constructs emerged: low self-confidence and optimistic views. These constructs aroused primarily because two contrasting perspectives were solicited.

Table 2

Frequency of Correct Responses in the Grammar Test of At-risk College Students $(N=51)$

\begin{tabular}{lccc}
\hline \multicolumn{1}{c}{ Grammatical/Linguistic Forms } & Number of Items & Frequency of Correct Responses & Percentage \\
\hline 1. Tense Aspect & 7 & 98 & 27.45 \\
2. Reported and direct speech & 6 & 86 & 28.10 \\
3. Kinds of phrases & 3 & 53 & 34.64 \\
4. Verbal phrases & 5 & 91 & 35.69 \\
5. Prepositions & 6 & 110 & 35.95 \\
6. Structures of sentences & 3 & 62 & 40.52 \\
7. Subject-Verb Agreement & 6 & 128 & 41.83 \\
8. Transitional markers & 4 & 93 & 45.59 \\
9. Verb voices & 8 & 210 & 51.47 \\
10. Conjunctions & 5 & 133 & 52.16 \\
11. Kinds of questions & 6 & 157 & 55.18 \\
12. Relative pronoun & 3 & 87 & 56.86 \\
13. Conditional sentences & 3 & 95 & 62.09 \\
\hline
\end{tabular}

Charting Confidence Issues - The thought of English as a difficult course lingered on some students' minds. Generally, this thinking affects their attitude, and their attitude influences their actions. Student (A) noted that "I don't' want to hear anymore English because I don't understand it...I think it's hard." In addition to this mindset was the fear to communicate orally for known reasons. Student (B) narrated that "I wanted to join the discussion...I'm shy is wrong. My classmates are laughing at my answers.” For some, pronunciation is a big issue. They are afraid of being laughed at; hence this condition seems to aggravate as learning anxiety. Such anxiety may have originated from past negative experiences. Another student (C) related high school moments. "My high school teacher required me to express myself in the second language, I tried my best but my best wasn't enough...I failed." This may explain why frustration is another factor impedes and/or is part of learning. Ironically, they could not shy away to such language since English is the language in almost all of their college courses. Thus, Al-Bustan and Al-Bustan (2009) justify that when ESL students wanted to be quiet in group works; they would normally get worried when they commit mistakes and they struggle to listen, read, speak and write in English.

College courses normally involve long list of reading and writing requirements. Failure to do one likely indicates poor reading and study habits. Student (D) and (E) shared such shortcomings when (D) wrote, "I forget to submit an assignment...I want to cheating with my classmate." and (E) complained, "There are many reading works and hectic schedule." Not only had such words existed, but also majority still needed to work doubly hard on their grammar which the test results disclosed. Student (F), interestingly, admitted his/her weakness in grammar when (F) reasoned out, "I week in grammar...I don't know it..." when F meant not being good at it. Hence, college English course is a challenge for most of them not to mention spelling and mechanics shortcomings. Learning-is-hard-because-it-is-not-my-mother-tongue notion prevailed in their composition, of which may be due to the fact that the primary language spoken at home is not English (Lee, 2011). The same case is even true in student-to-student interactions. Once everything has been written or said, it is always the morale or self-confidence of the students which is tested-to persevere in the college program or be part of the dropout statistics.

Making Best Opportunities - There are also opportunities which instructors can build on that could warrant a successful college program experience. More than ever, at-risk ESGP-PA student grantees were very much 
"thankful" for being given the chance to become college students which they considered one of the best things - being first ever member of the family to enter college; this very being strongly motivated them to pursue their dream of obtaining a college diploma. Hence, they understood well that it would not be a walk in the park. The need to learn more must be satisfied. Student $(\mathrm{G})$ stated, "English is not a reason for me to stop...I like to learn more the correct grammar, listening, speaking, reading, and writing." Another student (H) bragged, "It's very easy. I just follow instructions." For these students, doing things demands practice. This was justified when a handful of them shared what they had done: talking in English inside and outside the campus; writing good sentences; listening to English music; and learning from mistakes, to cite a few.

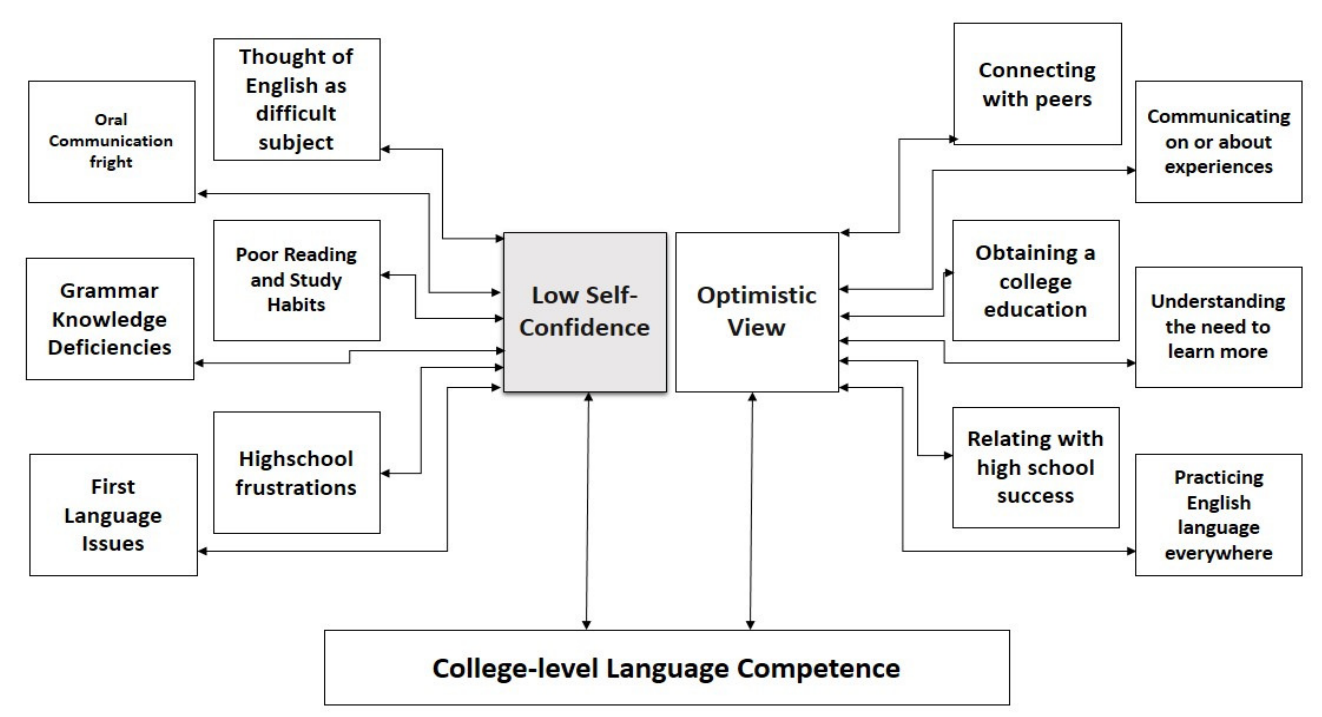

Figure 1. Simplified problematique map of at-risk college students' awareness toward developing English language competence

Group activities are appreciated by at-risk college students and the results are heartwarming. Student (I) hinted a favorable outcome- "I learn more, to collaborate to (with) others." Another student (J) led it with, “Group must be 'kapit bisig' (work as one) we must succeed in all activities." Moreover, college education is not just English course per se. Learners like to communicate the second language in whatever content as much as possible. Student (K) noted that, “...I read materials...I express what...I want to say.” One student (L) enjoyed the personalized approach in English language; (L) delighted writing about "My Idolized Person." Building on what the students have-cultural orientation, language, ways, interests, likes, etc. increases their connection or engagement with the language. After all, one could express English in so many subject or contents. Finally, success may not always be driven from failures; success in high school and previous experiences beget future success. It is essential that at-risk college students should not be at risk of losing the desire to learn. They have abundance of it. Students will perform better in L2 if they demonstrate the desire to learn English (Fullan \& Stiegelbauer, 1991). Their words of desire, happiness and I-can-learn attitude were almost present in their compositions. Unarguably, they remain optimistic as far their positive attitude is concerned.

\section{Conclusion}

This current study provides an alternative assessment of at-risk college students' second language and literacy skills, linguistic knowledge, and their awareness and experiences in academic literacy instruction. Although test items were inexhaustive, results suggest that the students found considerable level of difficulty in negotiating with meaning and form of college-level communicative language and tasks; consequently, critical reading skills of outlining, summarizing, identifying topic sentence, comprehending meaning of sentence to text level were their least learned competencies. Meanwhile, results of problematique analysis suggest that college 
It's not just English, it's complicated: Approaching at-risk college students' academic language remediation

students are perceived to be at risk when their confidence is challenged or engaged with the thought of English as a difficult subject, oral communication fright, poor study habits, grammar knowledge deficits, high school frustrations, and first/second language issues. On one hand, they express optimism in language learning by seeing themselves as actual college students sustained by state scholarship, connecting with peers, getting personal on their language and topic, understanding the urgency to learn, relating with previous successes, and practicing language inside and outside the university campus. More studies are encouraged to further support the claims and/or explore other influential factors that would pave the way to improved performance in academic literacy and second language learning. Granted that the generalizability of results is limited to the participating at-risk college students and language program enhancement, its relatability in some cases may contribute to the literature in approaching the issues concerning at-risk college learners.

\subsection{Remediation Implications}

The level of academic literacy and least learned skills or content in English language combined with the useful insights in keeping at-risk students confident and optimistic, suggest necessary and concrete action for the instructors and all concerned literacy professionals; hence there is a need for concerted effort in remediation programming and differentiated mentoring. The current short-term remediation session per subject area may be restructured to address the pressing needs and/or academic deficiencies of at-risk college students, so they can be more prepared to the progression of university courses. One way to do this is to regard all instructors as literacy instructors. And more importantly, to approach such program in a way that learners' desires, interests, orientation, knowledge levels, and background are well accounted for. This may sound long overdue, but regular evaluation and monitoring of program outcomes should still be put in place; just like what this paper had sought initially to achieve. Take note. It's not just English; it's complicated.

\section{References}

Al-Bayati, W. A. T. (2013). Errors made by Iraqi EFL undergraduates in the use of prepositions. Bulletin of the Transilvania University of Brasov, 6(1), 41-56.

Al-Bustan, S. A., \& Al-Bustan, L. (2009). Investigating students' attitudes and preferences towards learning English at Kuwait University. College Student Journal, 43(2), 454-463.

Assia, B., \& Said, K. (2014). The impact of small group interaction on learners' grammatical accuracy achievement. International Journal of Research Studies in Language Learning, 3(2), 85-100. http://dx.doi.org/10.5861/ijrsll.2013.511

Benesch, S. (1988). Linking content and language teachers: Collaboration across the curriculum. In S. Benesch (Ed.), Ending remediation: Linking ESL and content in higher education (pp. 57-66). Alexandria, VA: Teachers of English to Speakers of Other Languages.

Brown, H. D. (2002). Principles of language learning and teaching. Englewood Cliffs, NJ: Prentice-Hall.

Commission on Higher Education. (2012). Students' Grants-in-Aid Program for Poverty Alleviation (SGP-PA). Government Brochure. Quezon City, Philippines.

Curry, M. J. (2003). Skills, access, and basic writing: A community college case study from the United States. Studies in the Education of Adults, 35(1), 5-18.

Curry, M. J. (2004). UCLA community college review: Academic literacy for English language learners. Community College Review, 32(2), 51-68. http://dx.doi.org/10.1177/009155210403200204

Doloughan, F. (2001). Communication skills and the knowledge economy: Language, literacy, and the production of meaning. London: Institute of Education.

Donnelly, M. (1987). At-risk students. ERIC clearinghouse on educational management. Eugene, Oregon. Retrieved from http://www.ericdigests.org/pre-928/risk.htm

Fullan, M. G., \& Stiegelbauer, S. (1991). The new meaning of educational change. New York: Teachers College Press.

Genesee, F., \& Upshur, J. A. (1996), Classroom-based evaluation in second language education. Cambridge: 
Cacho, R. M.

Cambridge University Press.

Griffee, D. T. (2012). An introduction to second language research methods: Design and data. Retrieved from http://www.tesl-ej.org/wordpress/issues/volume16/ej64/ej64r3/

Hernandez, P. (2011). College 101: Introducing at-risk students to higher education. Retrieved from http://www.nea.org/assets/docs/2011TAHernandezFINAL.pdf

Jou, Y. S. (2013). Sociolinguistic approaches to identity negotiation and language learning: A circumstantiality perspective on communities of practice. International Journal of Research Studies in Language Learning, 2(1), 49-60. http://dx.doi.org/10.5861/ijrsll.2012.105

Lee, M. E. (2011). How to teach English to at-risk college students. Chronicle of Higher Education, 57(28), A33.

Lei, S. A., Berger, A. M., Allen, B. M., Plummer, C. V., \& Rosenberg, W. (2010). Strategies for improving reading skills among ELL college students. Reading Improvement, 47(2), 92-104.

Librero, F. R. (1993). Towards a methodology for problematique analysis: A Philippine experience. Asian Journal of Communication, 3(1), 84-102. http://dx.doi.org/10.1080/01292989309359574

Praise, S., \& Meenakshi, K. (2015). The importance of grammar in communication. International Journal of Research Studies in Language Learning, 4(1), 97-101. http://dx.doi.org/10.5861/ijrsll.2014.789

Vasquez, D. A. L. (2008). Error analysis in a written composition. Profile Issues in Teachers' Professional Development.

Vitale, M. R., \& Romance, N. R. (2012). A research-based strategy for inductively accelerating vocabulary acquisition of at-risk students in Grade 4. International Journal of Research Studies in Language Learning, 1(2), 33-46. http://dx.doi.org/10.5861/ijrsll.2012.v1i2.73

Wallace, C. (2007). Vocabulary: The key to teaching English language learners to read. Reading Improvement, 41(1), 189-193. 